\title{
GESTÃO DE MANUTENÇÃO DE FROTAS DE VEÍCULOS: UMA REVISÃO
}

\author{
Fernando Celso de Campos \\ Doutorando do Departamento de Engenharia Mecânica \\ Escola de Engenharia de São Carlos- USP. \\ Renato Vairo Belhot \\ Departamento de Engenharia Mecânica \\ Área de Engenharia de Produção \\ Escola de Engenharia de São Carlos- USP.
}

O presente trabalho descreve, sob a ótica gerencial, os problemas e os desafios enfrentados pelo setor de manutenção, nas empresas que operam frotas de veículos. $O$ contexto da manutenção é caracterizado a partir da discussão de questões ligadas a: qualificação da mão-de-obra, nível de informatização, complexidade do processo decisório e necessidade de conferir qualidade e produtividade ao funcionamento do setor.

Palavras-chaves: planejamento da manutenção, gerência de manutenção, controle da manutenção, manutenção de frotas de veículos.

\section{Introdução}

Historicamente, a manutenção, como regra geral tem apresentado uma característica marcante: utiliza de forma bastante ineficiente os seus recursos, principalmente humanos e materiais, acarretando custos elevados e crescentes.

Mão-de-obra e materiais representam as áreas com grande potencial para a redução dos custos de manutenção, caracterizando uma excelente oportunidade de ganhos imediatos, principalmente numa época de crise e de alta competitividade como a atual .

Hoje em dia, fica difícil ter uma boa manutenção, sem dispor de informações acuradas e atualizadas sobre cadastro de equipamentos, histórico de ocorrências, programação e planejamento de atividades, utilização de mão-de-obra, cronograma de paradas, emissão de ordens de serviço e controle de estoque, que auxiliam em muito a programação, a execução e o controle da "função manutenção".

A aplicação de recursos informatizados, ou sistemas informatizados, e ainda a tecnologia embarcada nos veículos, dia após dia vem fazendo surgir a necessidade de se reciclar e treinar a mão-de-obra envolvida com manutenção, chegando-se a propor (McDOWELL (1991)) até a aplicação de testes individuais para levantar e identificar as possíveis deficiências existentes em termos dessa mão-de-obra atuante. 
Pretende-se, neste trabalho, discutir, em relação à realidade brasileira, os problemas básicos da manutenção de frotas de veículos, como: custos, mão-de-obra, treinamento, e até situações de ponta como competitividade e produtividade.

Ora, é evidente que trabalhar dentro desses conceitos exige principalmente o treinamento dos gerentes, responsáveis pela tomada de decisões, e do pessoal técnico envolvido na área. O treinamento, ou capacitação, pode ser auxiliado pela adequação de um Sistema de Apoio à Decisão (SAD), para disciplinar e fornecer um conjunto de procedimentos mediante "sugestões" sistêmicas que favorecerão o encurtamento do tempo de preparação de uma decisão, bem como por tutoriais básicos e simples que sirvam de orientação na execução correta de algumas operações. Essa colocação é confirmada por MIRSHAWKA \& OLMEDO (1993, p. 40), quando afirmam que no ano de 1992 não mais que 30\% das empresas (entre as micros,pequenas e médias) que faziam a gestão das suas ordens de serviço usavam um processo informatizado.

Os aspectos da competitividade e terceirização de algumas atividades, são avaliados, discutidos e indicados como critério para a sobrevivência das empresas. A luta pela competitividade e em alguns casos pela própria sobrevivência, exige das empresas ocidentais respostas e ações com tal rapidez e em ambientes tão turbulentos, que as obriga a transitar sobre o tênue fio que separa o sucesso do fracasso. Descentralização da manutenção, subordinação ao segmento da manufatura, interação de sistemas de informação, preservação ambiental, terceirização e desverticalização, trabalho em grupo e desenvolvimento contínuo, constituem os desafios a serem vencidos.

É necessária uma mudança do padrão gerencial para que a empresa não perca a competitividade frente aos seus concorrentes mais imediatos. O Brasil está atrasado em relação aos países desenvolvidos, mas a velocidade da sua transformação indica que a revolução tecnológica de todos os setores veio para ficar.

\section{Considerações Gerais sobre Manutenção}

Existem várias terminologias divergentes para definir e conceituar as idéias, componentes ou até estados que a área de manutenção aborda. Algumas tentativas de padronizar a terminologia foram realizadas por alguns órgãos de normatização e grupos coordenadores dos diversos ramos industriais.

A Associação Brasileira de Normas Técnicas (ABNT (1971)) define manutenção como sendo o conjunto de todas as ações necessárias para que um item seja conservado ou restaurado de modo a poder permanecer de acordo com uma condição especificada. Essa associação também define defeito como sendo uma ocorrência no equipamento que não impede seu funcionamento, todavia podem, a curto ou longo prazo, acarretar sua indisponibilidade. $\mathrm{E}$ as falhas são definidas como ocorrências que impedem o funcionamento de equipamentos. Definem-se também os seguintes termos: taxa de falhas, vida útil, índice de confiabilidade, índice de disponibilidade, manutenção preventiva e manutenção corretiva.

O enfoque do gerenciamento econômico sustentado na relação entre materiais, máquinas e mão-de-obra, em função dos fatores de manutenção, desde o projeto de um 
equipamento até a sua liberação para alienação, corresponde à denominação na linha inglesa de: "Terotecnologia".

KELLY \& HARRIS (1980), citam o resultado das pesquisas de um Grupo de Trabalho do Ministério da Tecnologia do Reino Unido. O grupo de trabalho considerou que substancial economia poderia ser conseguida mediante o aperfeiçoamento da gerência de manutenção e um maior cuidado para com os fatores que afetam a manutenção, em todos os estágios do ciclo de vida dos equipamentos. Esta abordagem do ciclo de vida na redução dos custos de manutenção tem sido definida desde então como terotecnologia.

Numa empresa existe a necessidade de um plano de manutenção a curto prazo, que pode variar de alguns dias até meses, visando a adoção de políticas de manutenção apropriadas para as operações de reparo, substituição e recondicionamento dos sistemas e componentes, de modo que o processo decisório final seja o maior favorecido.

O plano de manutenção deve estar em conformidade com a estratégia de controles de recursos adotada pela empresa, uma vez que o custo de manutenção influencia sensivelmente as estruturas organizacionais e administrativas vigentes.

VIEIRA (1991), destaca que o serviço de manutenção possui duas características importantes:

a) é um processo caro, com seus gastos representando somas significativas ao longo da vida operacional dos equipamentos e instalações;

b) é um processo do tipo "mão-de-obra intensiva" e, ao que tudo indica, continuará a sê-lo mesmo que se lhe incorporem mais e mais avanços tecnológicos.

Portanto, o plano de manutenção deve estabelecer uma base racional para a formulação de um programa de manutenção preventiva e fornecer diretrizes para a manutenção preditiva.

O nível de eficiência da manutenção também está relacionado aos instrumentos e ferramentas utilizadas pelos mecânicos. Ficando difícil exigir serviços de boa qualidade e de alto grau de eficiência quando não se dispõe das ferramentas necessárias, sendo esse mais um aspecto que dificulta o planejamento da manutenção.

O planejamento da manutenção pode ter nos sistemas informatizados um aliado importante. $\mathrm{O}$ autor aponta um sistema que foi desenvolvido para auxiliar a gerência de manutenção na utilização eficiente dos recursos disponíveis, identificando as áreas críticas da situação a partir dos dados históricos que vão sendo armazenados numa base de dados. Destaca, também, que uma interface homem-máquina amigável, favorece a otimização e a análise do programa de manutenção vigente.

De acordo com KELLY \& HARRIS (1980) diversas políticas de manutenção podem ser aplicadas a uma empresa ou sistema organizacional, quer isoladamente quer combinadas, definindo assim a constituição do plano de manutenção pela aplicação dessas políticas:

I. Manutenção a intervalos pré-fixados, em que pode ocorrer substituição individual ou em grupo de componentes.

II. Manutenção baseada na condição do parâmetro, sendo assumida contínua ou periodicamente. 
III. Manutenção corretiva por reparo local ou por substituição de componente. É o procedimento de " operação até falhar " .

IV. Manutenção de oportunidade, usada normalmente quando o componente é complexo e demanda um tempo longo de manutenção.

V. Modificações de projeto.

Vale a pena observar que as ações efetuadas antes da ocorrência de uma falha são consideradas preventivas e, inversamente, as efetuadas após são consideradas corretivas.

As ações preventivas podem, portanto, ser programadas e executadas sob a forma de um plano de manutenção preventiva. A manutenção corretiva não pode ser programada, dada a natureza probabilística da falha e as incertezas que cercam a tomada de decisão correspondente.

É de vital conveniência que se avalie detalhadamente as políticas de manutenção antes até de se estudar um procedimento para determinar o plano de manutenção mais adequado.

A eficiência global em uma empresa que opera com frotas de veículos está vinculada ao desempenho da equipe de manutenção nas tarefas de planejamento, organização e execução das atividades da oficina. É objetivo do plano de manutenção reduzir as interrupções aleatórias no funcionamento das máquinas que executam os serviços. Assim, um programa de manutenção preventiva deve ser elaborado a partir de um minucioso estudo de cada peça ou parte principal dos veículos.

Em um plano de manutenção devem estar presentes sete condições:

a) estudar as condições reais de funcionamento dos equipamentos;

b) analisar as falhas e defeitos observados, sobretudo as falhas mais freqüentes;

c) analisar um sistema apropriado de lubrificação e normalização dos lubrificantes utilizados;

d) estudar o estoque mínimo de peças de reposição para evitar perdas de produção;

e) estudar as ferramentas especiais necessárias à manutenção e ao conserto dos equipamentos;

f) estudar possíveis modificações nas instalações, para permitir uma manutenção mais fácil e rápida;

g) estudar possíveis modificações de layout da oficina, de modo a evitar perda de tempo.

O plano de manutenção deve ser constituído pela melhor combinação das políticas de manutenção, coordenadas com o objetivo de promover uma melhor utilização do tempo e dos recursos disponíveis. É importante destacar que quando os componentes são de reposição simples, há uma aproximação do ideal nas ações preventivas e corretivas, pelo nível de detalhe fornecido pelo fabricante tornando a manutenção barata e determinística. Isso raramente ocorre para componentes de reposição complexa, cuja manutenção é custosa e probabilística.

Uma escolha cuidadosa de prioridades, em um plano de manutenção que seja gradativamente implementado, com vistas à manutenção preventiva, muitas vezes traz resultados economicamente mais relevantes do que o emprego de técnicas de manutenção preditiva, por exemplo. A atuação prioritária junto aos componentes 
"críticos" é fundamental para evitar uma manutenção muito cara. Ou seja, para defeitos ou falhas em componentes que não interrompem a operação dos veículos (buzina, janela, etc) pode-se dar uma maior flexibilidade nas intervenções sistemáticas, mas os defeitos ou falhas em componentes como pneus e baterias, entre outros, que podem interromper a operação, devem merecer maior grau de atenção.

Podem ser adotados como critérios para o estabelecimento de um plano de manutenção: horas de funcionamento, consumo de combustível ou quilometragem rodada. O primeiro critério se aplica melhor a motores estacionários devido à inexistência de odômetro; o segundo se adequa a operações do tipo "coleta de lixo" em que, mesmo com o veículo parado, há desgaste das peças do motor em funcionamento; o terceiro critério é o mais comumente usado para frotas de veículos.

Considera-se bastante aceitável uma composição a partir de 85\% de manutenção preventiva complementada pela corretiva. Para que se possa comprovar a economia obtida com o plano de manutenção implantado, deve-se realizar medidas anteriores e posteriores à sua aplicação.

A abordagem aqui feita não tem a intenção de esgotar o tratamento teórico da questão, mas simplesmente a de salientar a importância do planejamento das atividades de manutenção, destacando os itens que serão focalizados neste artigo.

\section{Aspectos Essenciais na Gerência de Manutenção}

A área de manutenção produz, no desempenho de suas funções, um conjunto considerável de anotações de controles referentes aos equipamentos que operam numa determinada empresa. Os dados gerados devem ser processados para a elaboração de relatórios, tabelas e gráficos, com conteúdos específicos, ciclo temporal conveniente e apropriados aos níveis de decisão.

Segundo TAVARES (1987), identificam-se quatro estágios de evolução dos sistemas de informação aplicados à manutenção: sistema de controle manual, sistema de controle semi-automatizado, sistema de controle automatizado e sistema on line.

Não basta contar com um sistema computadorizado, se não houver uma abordagem integrada para monitorar e controlar o custo dos materiais e da mão-deobra envolvida (em razão da interdependência existente entre o setor de manutenção e os outros setores da empresa).

É de primordial importância que o sistema de gerenciamento da manutenção tenha como principal característica a disponibilidade de meios para garantir: i) a transformação automática de dados, e sua transferência para outros setores, e ii) o retorno da informação (feedback).

Estes recursos serão valiosos quando da realização das revisões preventivas e também para a escolha das ocasiões em que será mais oportuno fazê-las. Essas são algumas das características abordadas por: DIPPENAAR(1988), PACHUCKI(1991) e SHERWIN(1990).

Os sistemas on-line estão relacionados com equipamentos (computadores) de grande porte, e a respeito desse tipo de arquitetura de sistema, CAMPOS (1993), chama a atenção para um aspecto a ser considerado com cuidado, que é o fenômeno do 
downsizing registrado como a grande tendência da década para as empresas que possuem esse tipo de equipamento.

Conforme MIZOKAWA et al. (1989), uma experiência feita numa grande empresa japonesa, envolvendo o projeto e a avaliação de um sistema de informação compacto e econômico, para controle da manutenção, usando microcomputadores interligados em rede, trouxe resultados excelentes em termos de flexibilidade e custo, tendo como base de comparação o sistema on-line de grande porte anteriormente utilizado.

Qualquer que seja a aplicação de sistemas de informação na administração e no gerenciamento da manutenção, se não houver um envolvimento efetivo dos profissionais desses setores desde a concepção e do desenvolvimento, até a implementação e testes, a implantação do sistema não terá êxito, nem mesmo os resultados tão aguardados e buscados.

Para se analisar resultados e redirecionar as diferentes estratégias da manutenção preditiva e preventiva KING (1990) e OKOGBAA et al. (1992) sugerem o desenvolvimento de uma base de dados históricos.

A aplicação dos recursos da informática à manutenção foi alvo de avaliações feitas por: GEHL (1989), HARPER (1989) e BALA KRISHNAN (1992), que falam sobre os cuidados que a gerência de manutenção, de uma forma geral, deve ter, no momento de optar por um sistema informatizado "de prateleira", em razão do fato de que esse tipo de sistema não atende completamente às necessidades levantadas.

Além disso, ressalta-se a grande (e inegável) potencialidade da aplicação do computador como ferramenta indispensável para o gerenciamento, considerando-se e avaliando-se clara e objetivamente algumas questões, tais como:

- o que o computador pode fazer pela manutenção?

- o que será necessário?

- qual o custo de instalação?

- quem usaria o sistema informatizado em lugar do sistema manual?

Para tanto, até se discute a aplicação de modelos de simulação em computador para avaliar as políticas de manutenção adotadas por uma empresa.

\subsection{Eficácia e eficiência no gerenciamento}

Para atingir seus objetivos, a organização precisa aplicar adequadamente os seus recursos produtivos, evitando o improviso. É necessário planejar antecipadamente e controlar adequadamente para obter a máxima utilização dos recursos e prestar o melhor nível de serviço ao cliente. Isto é, é preciso gerenciar com eficiência (utilização adequada dos recursos), dentro de padrões estabelecidos de eficácia (grau de sucesso na busca em atingir os objetivos).

Segundo LOBATO (1993), a vivência diária com os vários tipos de problemas de manutenção e a falta de treinamento gerencial, muito comum nesse meio profissional, levam a gerência de manutenção a gastar tempo demais em atividades de baixa importância, prejudicando sobremaneira o gerenciamento. Portanto, ele chama a 
atenção para os aspectos de organização e coordenação, de cada um dos participantes,individualmente.

Para COTTI (1989), a gestão eficaz da frota não é um processo que precisa ser necessariamente sofisticado, ou seja, necessariamente difícil, sendo que, muitas vezes, uma série de análises e decisões conduzidas pelo bom senso e pela preocupação real de melhorar o rendimento a cada dia, levam a resultados excelentes.

O controle informatizado garante a disponibilidade de informações gerenciais confiáveis, podendo definir a própria sobrevivência da empresa. No entanto, a informatização de um sistema ineficiente terá como resultado um fracasso informatizado. Haverá necessariamente uma perpetuação dos mesmos tipos de erro já existentes anteriormente. Afinal, nem todos os relatórios emitidos pelo computador são qualificados como informações.

Por isso, a elaboração de uma proposta bem estruturada vem qualificar acentuadamente o nível do serviço prestado ao usuário e estabelecer diferenciações competitivas, para as empresas do ramo de transportes que tenham como meta modernizar seus instrumentos de gestão e controle.

\subsection{0 processo decisório}

Dentro do processo de tomada de decisão existem três estágios: o PORQUÊ de se tomar uma decisão, ou seja, qual necessidade a gerou; o COMO essa decisão foi tomada, usando-se certos parâmetros, e o GRAU DE COMPLEXIDADE, referente à quantidade e volume de informações até se chegar aos parâmetros em que se fundamenta a decisão.

A tomada de decisões no âmbito da gerência de manutenção atravessa inevitavelmente as fronteiras departamentais, por necessitar de informações de diversas fontes, em cada um dos aspectos relacionados com sua função, seus objetivos, sua estrutura organizacional e suas ações. Tais decisões podem variar em importância desde a substituição de um equipamento principal até um pequeno reparo. É importante portanto entender a estrutura do processo de tomada de decisões.

Segundo KELLY \& HARRIS (1980) existe um problema decisório quando: há um objetivo em vista; existem pelo menos duas alternativas de ação; há incerteza quanto à melhor alternativa e estão presentes fatores externos, fora do controle de quem toma a decisão, que podem afetar o resultado. A identificação da melhor alternativa de ação só é possível se os fatores que influenciam o problema forem bem compreendidos.

Os fatores mais importantes seriam possivelmente a causa das falhas, sua incidência com relação ao tempo, os custos de manutenção, os custos da modificação do projeto e os elementos não quantificáveis, relacionados com a receptividade de um programa de manutenção preventiva.

Nem sempre é possível, ou desejável, estabelecer regras muito rígidas para o processo decisório, mas é absolutamente essencial assegurar que os objetivos da manutenção sejam claramente compreendidos em todos os níveis, e que os sistemas de 
informação sejam projetados para fornecer a informação correta, à pessoa certa, na ocasião propícia.

A disseminação da informática, sem dúvida, vem tendo ampla repercussão e produzindo ganhos substanciais a saber: rapidez de execução, eficácia no trabalho, melhoria do padrão de serviços, grande quantidade de informações que podem ser armazenadas para uso futuro, entre outros.

Parece ser um consenso que o nível refinado de tomada de decisões em manutenção está sendo evidenciado gradativamente com o uso dos recursos da informática, principalmente com o advento da divulgação massiva do microcomputador e o decréscimo do seu custo, bem como das aplicações de redes, facilitando a interligação entre os departamentos e favorecendo um aumento da velocidade de circulação da informação, sem falar nos diversos recursos de software e hardware que vêm facilitando em muito a vida de qualquer usuário.

Para RIBEIRO (1989), a aplicação da tecnologia da informática, como instrumento de apoio aos processos decisórios e gerenciais, ainda é incipiente. Somente uma postura consciente e madura dos empresários, com relação à informática, poderá aumentar a expectativa de tornar real o planejamento adequado, a obtenção de decisões fundamentadas, operações ágeis e controles eficientes.

Porém, para REGRA (1993) é necessário encarar com cautela o uso desses recursos, face à qualidade da informação que esse uso oferece. Por isso ele afirma: "Muitos sistemas se limitam a informar quanto está custando a frota. Isso não basta! É preciso que ele mostre onde e como reduzir custos e ganhar competitividade (...) que faça análises comparativas e gere relatórios que facilitem a tomada de decisões"

Ao citar a importância da ciência da computação junto à tecnologia da informação, vale ressaltar que o computador é apenas uma ferramenta de aplicação no sistema e, por si só, não o representa na íntegra. A análise das informações, por exemplo, é vital para que se alcance um rendimento satisfatório.

BURCH (1979) afirma que muitos empresários criticam duramente a informatização de sistemas por três razões:

- grandes expectativas que não obtiveram êxito;

- falta de análise adequada;

- síndrome da computeritis que representa a aquisição de computadores como solução para todos os problemas.

Para GUERRA (1992) a aplicação gradativa das técnicas de manutenção preditiva é fundamental na ajuda do processo de tomada de decisões e deve ocorrer como forma de se obter o estado dos componentes dos veículos e reduzir os custos de manutenção. Por exemplo, o acompanhamento da variação da condição do óleo nos motores dá idéia do estado dos filtros, bombas de óleo, tubulações, etc. Esses dados, levados a um gráfico, em função do tempo, indicarão o grau de desgaste das diferentes partes do motor, informação que é um dado importante para instruir a tomada de decisão quanto a novas aquisições de componentes para reposição, ou até de novos motores para ficarem de sobressalentes.

Consideram-se também dignas de análise as variáveis: tipo de linha em relação ao piso, quantidade de passageiros transportados, topografia da linha, quantidade de 
paradas, quantidade de curvas, tipo de combustível, tipo de chassi, idade do veículo, tipo de freio, condições de operação, etc, como fundamentais e determinantes num processo de tomada de decisões, devido ao fato de que, variando-se uma dessas citadas condições e mantendo-se as demais constantes, faz-se necessário realizar mudanças na programação da manutenção.

À medida que o número de veículos da empresa cresce, exige-se maior rigor nas várias etapas de coleta de informações para controles e simultaneamente elas tornamse mais complexas. Mediante a utilização de um adequado aparato de controle de informações, os custos e o rendimento da frota tornam-se visíveis, o que possibilita decisões oportunas e racionais.

Ao longo do desenvolvimento da atividade de manutenção são geradas e coletadas inúmeras informações, que devem ser convenientemente tratadas no mais breve espaço de tempo possível para produzirem relatórios, tabelas e gráficos, com conteúdos próprios, concisos e tratados de acordo com os níveis funcionais a que se destinam, oferecendo alternativas para a tomada de decisões. Portanto, um grande volume de minuciosas atividades, interligadas entre si, caracteriza a área de manutenção das empresas de transportes.

SILVA \& CAMPOS (1993), afirmam que, numa empresa de transportes, a complexidade do sistema deve-se à grande diferenciação e quantidade de itens, que atingem a casa dos milhares.

A interdependência dos controles e os detalhes de execução são os maiores responsáveis pela complexidade do planejamento dos programas de manutenção.

O grande volume de informações, a dimensão dos custos e o valor patrimonial dos veículos e equipamentos, mais a conjuntura econômica, tornam fundamental uma administração ao mesmo tempo eficiente e abrangente, em função da complexidade que todos esses fatores citados geram. Num mercado competitivo, as empresas precisam dispor de informações gerenciais confiáveis e de modernas ferramentas de controle operacional. É vital reduzir custos.

Ao tomar decisões, os gerentes normalmente utilizam-se de uma série de fontes de informação. Dependendo do estilo pessoal do gerente a ênfase colocada em diferentes informações certamente vai variar.

\subsection{Qualidade e produtividade}

Com o objetivo de buscar a modernização do país, foram lançados,em 1991,o Programa Brasileiro de Qualidade e Produtividade (PBQP) e o Programa de Competitividade Industrial (PCI).

NEVES (1992), a partir de uma pesquisa, patrocinada pela Price Waterhouse, envolvendo empresas privadas brasileiras de médio e grande porte, demonstra que há uma tendência, cada vez mais crescente, para aumentar a produtividade e a qualidade, embora essas organizações ainda estejam longe de conseguir maximizar o uso dos recursos disponíveis . 
MIRSHAWKA (1991), olhando esse panorama afirma que: "Alguns segmentos empresariais estão adotando a qualidade e confiabilidade dos serviços e produtos como meta maior. O setor de manutenção também precisa assumir esta postura".

A garantia da qualidade e produtividade advém de um grupo de atitudes ao longo de todo o processo de execução da manutenção, influenciada por fatores técnicos, humanos e da organização e gestão empresarial.

O fator deficiente para se alcançar produtividade com qualidade em manutenção pode ser a motivação do pessoal. Identificadas as causas e realizando reuniões periódicas, a equipe gerencial pode atingir o objetivo de melhoria da qualidade e produtividade, permitindo inclusive traçar novos horizontes.

Para assegurar e manter a qualidade dos serviços prestados, pode-se utilizar o Programa de Garantia da Qualidade na Engenharia de Manutenção (PQuEM), que, sem usar ferramentas sofisticadas, focaliza sua atuação no elemento mais importante de todos: o homem de manutenção (NAZARENO et al. (1993) e ESDRAS (1993)).

MIRSHAWKA (1991), afirma que o Controle de Qualidade da Manutenção (CQM) reduz os custos ocasionados pela falta de qualidade, tais como, entre outros, os decorrentes de: perdas por quebra de produção, má utilização de materiais e mão-deobra, esforço de recuperação da imagem externa, e acidentes diversos. É a revolução de mentalidade na qual o Qualium vence o Quantum.

A produtividade do setor de manutenção corresponde ao máximo aproveitamento dos recursos produtivos, conseguido pela aplicação de técnicas de manutenção preventiva, para que todas as intervenções ocorram no momento correto.

Essa idéia também é compartilhada por VIANNA (1993), ao afirmar que a obsolescência programada é a base da manutenção preventiva programada ou sistemática, que evita ou diminui paradas imprevistas, e portanto reduz os custos operacionais.

Para se obter qualidade na manutenção, buscando atingir Zero Defeitos, deve-se levar em consideração: a qualidade da mão-de-obra, a qualidade do serviço, uma auditoria da qualidade e um programa de ação corretiva.

A meta da Manutenção Produtiva Total (TPM) consiste na obtenção de melhor rendimento para o sistema de produção, mediante a participação de todos os empregados nas atividades da manutenção produtiva.

MORAIS (1993), comenta os efeitos de um programa de TPM aplicado em uma empresa desde a sua implantação, descrevendo todas as atividades executadas, e avalia os resultados finais, que são: aumento da disponibilidade dos equipamentos de 90 para 95.3\%; redução dos custos de manutenção de US\$ 285 para US\$ 92 por equipamento/mês; melhoria na higienização das áreas operacionais e aumento da satisfação dos trabalhadores envolvidos.

RODRIGUES \& PEREIRA (1993), relatam aplicações de ferramentas de gerenciamento da qualidade total, que viabilizaram a implantação de um programa de manutenção preditiva, passando a ter uma eficácia impressionante.

É possível atingir metas, em direção ao Zero Defeito, mediante cuidados elementares utilizados para combater causas potenciais de falhas, tais como: desgastes, corrosão, trincas, ruído, vibração excessiva, folgas e sujeira. 
Na concepção de alguns autores, o ideal em manutenção não é reparar o equipamento e deixá-lo como era anteriormente, mas sim repará-lo e deixá-lo melhor do que era quando novo.

SCHEUER (1993), citando uma pesquisa feita recentemente pela American Quality Foundation e pela consultoria Ernst \& Young, em quatro países: Canadá, Japão, Alemanha e Estados Unidos, fornece boas indicações de como obter práticas gerenciais de qualidade. Ficou constatado que o processo de gerenciamento da qualidade se auto-alimenta.

\section{Diagnóstico da Manutenção de Frotas de Veículos}

A partir do momento em que uma empresa tenha um veículo, passa a fazer sentido uma preocupação com a administração racional desse bem. Isso se justifica por várias razões:

a) veículos são bens de produção, de custo elevado;

b) veículos são bens "que se movem", criando oportunidade para atritos, desgaste decorrente das condições ambientais, danos ao próprio veículo, a outros veículos, a pessoas, como o motorista, o ajudante ou terceiros;

c) veículos transportam pessoas e também bens materiais, de valor às vezes muito elevado, desempenhando um papel de extrema importância em diferentes sistemas produtivos;

d) a empresa precisa ter um adequado retorno sobre o investimento com seus veículos, para preservar seu poder de reposição e garantir sua competitividade.

Ressalte-se ainda que a manutenção de frotas de veículos está sujeita a certas condições e fatores ambientais que a tornam particularmente complexa.

Entre esses fatores podem ser citados: o estado da malha viária, a taxa de ocupação a que estão sujeitos os veículos, em relação à sua capacidade nominal, a atuação de mercado dos fabricantes e encarroçadores, além da capacitação da mão-deobra envolvida na operação e manutenção dos veículos.

A seguir são discutidos os principais problemas enfrentados nesse campo de atuação.

\subsection{Qualificação da mão-de-obra}

A área de manutenção ainda recebe pouca atenção por parte dos empresários do setor de transportes. Nos últimos anos, com a descapitalização do setor, o arrocho tarifário, o gerenciamento mais rigoroso do sistema e o conseqüente envelhecimento da frota, os controles preventivos e corretivos assumiram uma posição de maior destaque. Esses fatores passaram a imprimir sérias dificuldades ao processo de tomada de decisões.

Segundo CATALAN (1993), a heterogeneidade dos parques industriais brasileiros e a crise econômica que o país atravessa, responsável por políticas de contenção de recursos e a falta de reposição de mão-de-obra qualificada, tornam ainda mais árdua a tarefa de gerenciar a atividade de manutenção no Brasil. 
Um veículo convencional, no valor de aproximadamente US\$ 100 mil (cem mil dólares), é, muitas vezes, mantido por pessoas semi ou completamente analfabetas e despreparadas tecnicamente em termos de manutenção, sem falar na mão-de-obra de condução (motoristas).

O grau de instrução dos integrantes das equipes de manutenção, em várias regiões do Brasil, impede que esses profissionais obtenham aproveitamento satisfatório nos cursos de treinamento a que são submetidos. Não é raro que os mecânicos acabem sendo meros trocadores de peças, que nem sequer, questionam as causas das falhas ocorridas nos componentes.

Dentre outros fatores que concorrem negativamente para instaurar essa situação podem ser citados: a discriminação, a desvalorização profissional e a baixa remuneração. Os salários pagos aos mecânicos são, muitas vezes, inferiores aos dos motoristas, contribuindo para acentuar ainda mais o quadro de desqualificação na área de manutenção.

Os investimentos realizados na qualificação do pessoal, se autofinanciam, a médio prazo, pela melhoria da eficiência dos serviços e pelo incremento dos lucros reais. A qualificação deve alcançar todos os recursos humanos envolvidos na manutenção.

\subsection{Estabelecimento do plano de manutenção}

Os departamentos de manutenção geralmente adotam os planos preventivos recomendados pelos próprios fabricantes dos veículos, ou criam os seus a partir deles.

Estes planos quase sempre sugerem inspeções, lubrificações e substituições periódicas de determinados componentes mecânicos. A vida útil dos itens dificilmente é fornecida e, quando indicada, situa-se completamente fora da realidade aplicável.

Segundo GUERRA (1992) nas visitas técnicas realizadas em empresas com frotas de veículos, em algumas regiões do Brasil, a explicação dada pelos empresários, com relação à origem dos valores de quilometragem entre revisões preventivas, foi única: empirismo. Todas as empresas visitadas trabalham com múltiplos de 10.000 Km para execução dos planos preventivos. Este valor tem forte influência de um fabricante monopolizador do mercado nacional.

GUERRA (1991), afirma que considerável variação é percebida para os intervalos de troca de óleo lubrificante numa mesma cidade, onde se encontram empresas trabalhando com valores bem distintos para lubrificantes de classes iguais e condições de serviço equivalentes. Isso porque poucas empresas adotam o uso de laboratórios para análise de óleo lubrificante com fins de pesquisa com relação a possível dilatação dos intervalos de substituição do fluido. Quando as análises ocorrem, são feitas apenas para acompanhamento da vida do motor.

SILVA \& FERRAZ (1991), destacam que outra grande variação detectada é a que se verifica quanto aos intervalos de substituição das lonas de freio. Naturalmente, o consumo de lonas é influenciado por uma grande variedade de fatores, entre os quais figura a topografia das cidades e estradas, bem como o modo de operar o veículo. 
Não existe um banco de dados para a manutenção, que permita pesquisas aprofundadas com relação aos intervalos de substituição de itens para as diversas situações de operação dos veículos.

\subsection{Nível de informatização}

GUERRA (1991), participou de várias reuniões na sede do Sindicato Nacional de Transportes Urbanos (SNTU), em Brasília, onde manteve contato com empresários do país inteiro, em termos do nível de informatização da manutenção. Deparou-se com alguns empresários que afirmaram possuir sistemas de manutenção informatizados. A constatação in loco revela, porém, uma realidade bem diferente no que toca aos controles de manutenção.

Num determinado momento GUERRA (1991) afirma: "O simples fato de possuir computadores controlando intervalos de revisões induz, erroneamente, alguns empresários a imaginarem-se detentores de um sistema de manutenção totalmente informatizado. Em geral, as empresas utilizam os computadores para elaboração de folhas de pagamento, contabilidade e alguns controles de tráfego. A área de manutenção recebe pouca atenção das empresas em relação ao processo de informatização. A utilização do computador como um instrumento de apoio à decisão, nesta área, é pouco significativa!"

A administração de frotas de veículos é uma área onde a informatização é extremamente necessária e benéfica, mas que se encontra pouco informatizada mesmo em empresas multinacionais.

Embora grande parte das empresas reconheça o fato, há em muitos casos uma resistência à implantação de um plano diretor de informática, que auxilie todos os setores, de uma forma integrada e eficaz, agilizando o fluxo de informações e conseqüentemente melhorando o nível das decisões tomadas.

Grande parte dos gerentes das empresas visitadas conhece a importância da integração das áreas de tráfego e materiais com a manutenção. Não se identifica, porém, a existência de um sistema de informações gerenciais que formalize os fluxos de informação mais importantes dessas áreas e que sirva de apoio aos processos de decisão da empresa como um todo.

\section{Conclusão}

O mercado mundial, em linhas gerais, tem apregoado e disseminado alguns critérios e padrões para os setores primário, secundário e terciário da economia, que podem ser sintetizados como um incremento da qualidade e um aumento da produtividade, buscando a redução de custos para a garantia da competitividade e da sobrevivência das empresas.

Para as empresas de frotas de veículos não é diferente, pois utilizam, no exercício de suas atividades, um insumo que atinge valores de dezenas a até centenas de milhares de dólares, que são os veículos. Portanto, uma atenção especial deve ser dada ao processo de manutenção, para que a operacionalização de sua finalidade 
primeira, ou seja, realizar transportes, seja atendida plenamente em todos os seus aspectos. Para que esse atendimento seja pleno, livre de empecilhos, a função manutenção deve estar atuando dentro de padrões garantidos de qualidade e produtividade.

Esses padrões de qualidade e produtividade podem ser compreendidos como tendo várias facetas, que congruentemente o viabilizam. Dentre elas: um melhor planejamento da manutenção; o uso da manutenção produtiva total (TPM), visando a implementação de programas de treinamento e capacitação adequados para a gerência de manutenção e para a mão-de-obra envolvida com as tarefas da manutenção; estudo e implantação de redução de custos; planejamento de compras e dimensionamento dos estoques de componentes sobressalentes; aplicação de recursos de informática e sistemas de informação; aplicação de SAD e, por fim, a busca equilibrada da terceirização.

Em termos do estudo e implementação de redução de custos, como CASTRO (1993) descreve, no âmbito exterior ou nacional, as áreas de mão-de-obra e de materiais são as que mais se destacam no tocante à necessidade de redução de custos. Porém, poucas contribuições têm surgido, capazes de resolver ou simplificar o problema, cuja solução abriria uma excelente oportunidade de ganhos imediatos.

O planejamento de compras e o dimensionamento dos estoques de componentes sobressalentes, é outra área potencial para a melhoria do sistema global de manutenção.

A questão da terceirização constitui um tema bastante atual, considerando a movimentação mundial no sentido de repassar a responsabilidade por certas atividades, do ponto de vista de custos. Sobre o assunto podem ser consultados CARVALHO (1993), CASTRO (1993), PINTO (1993) e SROUR (1993).

A aplicação de SAD em frotas de veículos em geral, abre uma área de pesquisa promissora, em razão da importância da aplicação de sistemas de informação, e considerando-se o atual nível de informatização e os processos decisórios adotados pelas empresas. Nessa linha de atuação podem ser citados os trabalhos de GUERRA (1992) e CAMPOS (1994).

Assim, na transformação que se vai sedimentando aos poucos e para vencer esta crise mundial, os futuros especialistas de manutenção deverão estar familiarizados com as técnicas e procedimentos de informática, inclusive no sentido de influir na especificação e projeto de hardware e software específicos. Porém, o emprego da informática em uma organização pode gerar uma possível reação em cadeia, criandose uma exigência maior ou menor de qualificação para o desempenho de tarefas, afetando inclusive a divisão do trabalho.

\section{Referências Bibliográficas:}

ABNT - TB - 19 Grupo 05: Termos fundamentais de eletricidade, 1971. 
ALTER, S.: "A taxonomy of decision support systems". Sloan Management Review, 9 (1), p.39-56, 1977.

BALA KRISHNAN, N.T.: "A simulation model for maintenance planning". In: Proceedings of the 1992 Annual Reliability and Maintainability Symposium, Las Vegas, NV, USA, Jan 21-23, 1992, p. 109-118.

BURCH, J.G. et al.: Information systems: theory and practice. John Wiley \& Sons, London, 1979.

CAMPOS, F.C.: "O homo informaticus e o fenômeno do downsizing". Jornal O Diário, Coluna Informatec, São Carlos, 12/09/1993.

CAMPOS, F.C.: Um sistema de apoio à decisão em gerência de manutenção de frotas de veículos. Dissertação de Mestrado, EESC-USP, (113 p.), 1994.

CARVALHO, L.T.: "Manutenção e a arquitetura organizacional competitiva". In: Anais do 8.o Congresso Brasileiro de Manutenção, São Paulo, outubro/1993.

CASTRO, D.A.: "Uma abordagem sobre a baixa performance da manutenção". In: Anais do 8.o Congresso Brasileiro de Manutenção, São Paulo, outubro/1993.

CATALAN, D.: "Desafios do gerenciamento de manutenção". Revista Manutenção, n.40, (p.31-34), 1993.

COTTI, L.R.M.C.: Formulários para administração racional da frota. Ed. Síntese Ltda., São Paulo, 1989.

DIPPENAAR, D.: "Integrated maintenance information management". South Africa Mechanical Engineer, v.38, n.11-12, 1988.

ESDRAS, R.L.: "PQuEM - Programa de garantia da qualidade na engenharia de manutenção". In: Anais do 8.o Congresso Brasileiro de Manutenção, São Paulo, outubro/1993.

GEHL, P.: "Choosing a computerized maintenance management system". SME Technical Paper (series) MS 1989, var paging MS 89-341.

GUERRA, A.R.O.: "Desenvolvimento de um sistema de informações como apoio às atividades de manutenção de uma empresa de transportes urbanos rodoviários". In: Encontro Nacional da ANPAD, 15., Belo Horizonte - MG, p.79-87, 1991.

GUERRA, A.RO.: Gerência de manutenção de frota de ônibus - um sistema de apoio à decisão. Dissertação de Mestrado - Universidade Federal do Rio Grande do Norte, Natal, (288 p.), 1992.

HARPER, N.: "Computer as a maintenance tool", Internationale SeilbahnRundschau, n.3, p.21-22, Aug-Sep/1989.

KELLY, A. \& HARRIS, M.J.: Administração da manutenção industrial. IBP, 1980.

KING, D.J.: "Administrators and computerized maintenance management systems a case of study". Biomedical Instrumentation \& Technology, v.24, n.4, p.254-258, Jul-Aug/1990.

LOBATO, J.O.R.: "O gerente de manutenção atropelado pelo dia-a-dia". In: Anais do 8.o Congresso Brasileiro de Manutenção, São Paulo, outubro/1993.

MCDOWELL, J.: "Electronics maintenance truck and bus fleets". SAE Technical Paper Series, Nov./1991. 
MIRSHAWKA, V. \& OLMEDO, N.L.: "Manutenção participativa". Revista Qualimetria, n.19, p.35-41, Março/93.

MIRSHAWKA, V.: Manutenção preditiva. McGraw-Hill, São Paulo, 1991.

MIZOKAWA, T. et al.: "Maintenance information control system using personal computers in LAN environment". Research \& Development (Kobe Steel Ltda.). v.39, n.4, p.35-41, Oct/1989.

MORAIS, V.O.: "TPM - manutenção produtiva total - aplicação prática na refinaria da ALUMAR". In: Anais do 8.o Congresso Brasileiro de Manutenção, São Paulo, outubro/1993.

NAZARENO, C.; COSTA, H. R.; BARROS, W.L.S.: "A missão qualidade". In: Anais do 8.o Congresso Brasileiro de Manutenção, S.Paulo, outubro/1993.

NEVES, A.C.: "Indicadores de qualidade e produtividade". Revista Controle da Qualidade, S. Paulo, n.10, p.10-13, set-out/1992.

OKOGBAA, G.; HUANG, J.; SHELL, R.L., "Database design for predictive preventive maintenance system of automated manufacturing system". Computers \& Industrial Engineering, v.23, n.1-4, p.7-10, Nov/1992.

PACHUCKI, W.J.: "Computerized maintenance management information systems. a valuable tool". Mining Engineering, v.43, n.1, p.33-35, Jan/1991.

PINTO, A.K.: "A terceirização na manutenção: redução de custos ou opção estratégica?". In: Anais do 8.o Congresso Brasileiro de Manutenção, 1993.

REGRA, J.: "Frota: menos custo, mais lucro". Jornal Direção, n.1, 1993.

RIBEIRO, P.J.A.: "Planejando a informatização na empresa: considerações e diretrizes". Planejamento e Gestão, v.1, n.2, set/1989.

RODRIGUES, H. \& PEREIRA, C.A.: "Implantação de manutenção preventiva utilizando ferramentas do gerenciamento da qualidade total na SUPEL CVRD". In: Anais do 8.o Congresso Brasileiro de Manutenção, São Paulo, outubro/1993.

SCHEUER, L.A.: "Qualidade, uma tendência mundial". Revista Manutenção, Rio de Janeiro, n.44, p.3, set-out/1993.

SHERWIN, D.J.: "Design for a comprehensive maintenance planning recording and optimization system". Engineering Costs and Production Economics, v.20, n.1, p.37-42, Jul/1990.

SILVA, A.N.R. \& FERRAZ, A.C.P.: Transporte público urbano operação e administração, Public. EESC-USP 063/91, São Carlos, julho/1991.

SILVA, A.V. e CAMPOS, D.F.: "Gestão de materiais em uma empresa de transportes urbanos rodoviários: uma abordagem sistêmica". In: Anais do XIII Encontro Nacional de Engenharia de Produção (ENEGEP), Florianópolis, p.1092-97, Outubro/1993.

SROUR, R.H.: "A que veio a terceirização". Revista Treinamento \& Desenvolvimento, São Paulo, n.2, p. 26-30, jan/1993.

TAVARES, L.A.: Controle de manutenção por computador. JR Ed. Técnica, 1987.

VIANNA, L.P.: "Obsolescência programada: um benefício da manutenção de primeiro mundo". In: Anais do 8.o Congresso Brasileiro de Manutenção, São Paulo, outubro/1993. 
VIEIRA, M.G.: Introdução à manutenção. Publ. EESC-USP, nro.017/92, São Carlos, (15 p.), 1991.

\section{Bibliografia Complementar:}

ALVAREZ, O.E.: Manual de manutenção planejada. Universitáriaria UFPB, João Pessoa,1988.

BERMUDES JR., O.: "Ônibus de luxo conquista a preferência dos turistas". Revista Eu Rodo, Publicação da Volvo do Brasil Veículos Ltda, São Paulo, n 65, p.4-9, julho/1993.

BLOCH, H.P. \& CARROLL, J.R.: "Preventive maintenance can be more effective than predictive programs". Oil and Gas Journal, v.88, n.31, p.81-86, Jul./1990.

BUEHRING, V.; UHLEMANN, K.D.; WILHELM, K.: "Computer-aided disposition of the reserve of spare parts". Engineering Costs and Production Economics, v.19, n.1-3, p.133-137, May/1990, .

CAMPOS, D.F. \& GUERRA, A.R.O.: "Manutenção de frotas de ônibus: um sistema de apoio à decisão". In: Anais do XIII Encontro Nacional de Engenharia de Produção (ENEGEP), Florianópolis, v.2, p.1077-1081, 1993.

CARVALHO, R.S.N. \& ALVES, J.E.: "Manutenção baseada em confiabilidade (MBC) na Petroflex". In: Anais do 8.o Congresso Brasileiro de Manutenção, São Paulo, outubro/1993.

COUSINS, L.; DAILEY, W.; PUZNIAK, T.J.: "PC based analyzer maintenance management system". In: Proceedings of the 34th ISA Analysis Division Symposium, v. 23, p.133-147, May 11-13/1988.

CUNHA, C.J.C. \& GUIMARÃES, V.N.: "O significado de racionalidade em problemas de decisão". In: Anais do XIII Encontro Nacional de Engenharia de Produção (ENEGEP), Florianópolis, v. 2, p.1025-1029, outubro/1993.

DELLAGNELO, E.H.L.: "A informática e a divisão do trabalho: um caso para análise". In: Anais do XIII Encontro Nacional de Engenharia Produção (ENEGEP), Florianópolis, v.2, p.1273-1278, out/1993.

DUFFUAA, S.O. et al.: "Evaluation of maintenance systems". Journal of King Saud University, Engineering Sciences, v.4, p.29-43, 1992.

GALLEGOS, J.: "Manutenção baseada em confiabilidade". Revista Manutenção, (Rio de Janeiro), n.44, p.23-26, set-outubro/1993.

GORRY, G.A. \& MORTON, M.S.S.: "A framework for management information systems". Sloan Management Review, vol. 13, pp. 55-70 Fall 1971.

GRAHL, E. \& MERLO, R.B.: "Um protótipo de gerador de sistemas de apoio à decisão". In: Anais do XIII Encontro Nacional de Engenharia de Produção (ENEGEP), Florianópolis, v.2, p.116-1121, out/1993.

GUERRA, A.R.O. et al.: "Sistema de informação como apoio às atividades de manutenção de uma empresa de transportes urbanos rodoviários". In: CEM-NNE/91, Anais Natal (RN), DEM/UFRN, p.321-28, 1991. 
HAM, I.: Industrial engineering handbook. John Wiley \& Sons, Inc. Publishers, 1987.

HIND, D. J.: "Maintenance - the state of the art". Mining Technology, v.71, n.819, p.10-13, Jan/1989.

HOGUE, J.T.: "Uma estrutura para análise do envolvimento da gerência em sistemas de apoio à Decisão". In: SPRAGUE JR., R.H. \& WATSON, H.J.,Coletânea: Sistema de Apoio à Decisão Colocando a Teoria em Prática. Ed. Campus, Rio de Janeiro, p.57-75, 1991.

KNEZEVIC, J.: "Reliability and maintenance". Gas Engineering and Maintenance, v.30, n.1, p.8-14, Jan/1990.

KOSTIC, S. \& PENDIC, Z.: "Optmization of spare parts in a multilevel maintenance systems". Engineering Costs and Production Economics, v.20, n.1, p.93-99, Jul/1990.

LINZMAYER, E.: Administração de materiais. Curso de Manutenção Industrial, Instituto Mauá de Tecnologia, 1985.

LUKICH,J. M. \& BRANDT, W. D.: "Integrated diagnostics for the vehicle system". SAE (Society of Automotive Engineers) Transactions, v.100, n.2, p.503-509, Sept/1991.

MARCH, J.G.: "How decisions happens in organizations". Human-Computer Interaction, v.6, n.2, p.95-117, 1991.

NAJJAR, R.: Manutenção de frotas e equipamentos móveis. Curso de Manutenção Industrial, Instituto Mauá de Tecnologia, 1984.

NEPOMUCENO, L. X.: Técnicas de manutenção preditiva. Ed. Blucher, São Paulo, 1989.

NOVAES, A.G.: "Pré-seleção do tipo de veículo para distribuição física de produtos". In: Anais do XIII Encontro Nacional de Engenharia de Produção (ENEGEP), Florianópolis, v.2, p.1082-1087, outubro/93.

OLIVEIRA, L.W.: "A segurança da boa manutenção para evitar acidentes de trânsito". In: Anais do 8.o Congresso Brasileiro de Manutenção, S. Paulo, out./1993.

REGRA, J.: "Na direção certa". São Paulo, Jornal Direção, n.1, 1993.

REGRA, J.: "Controle de frota informatizado: custos e benefícios". Jornal Direção, S. Paulo, n.1, 1993.

SALATA JR., F.R. \& YOSHIZAKI, H.T.Y.: "Modelo de apoio à decisão de roteamento na distribuição física de produtos perecíveis". Revista Produção, v.3, n.1, p.45-51, maio/1993.

TAVARES, L.A.: "Análise e diagnóstico - nova modalidade para melhoria do processo de gestão da manutenção". In: Anais do 8.o Congresso Brasileiro de Manutenção, São Paulo, out/1993.

TEIXEIRA, J.E.: "Muito além da fé e da competência técnica". Revista Treinamento \& Desenvolvimento, São Paulo, n.2, p.14-18, jan/1993.

THESIN, M. et al.: "Custos de pneus e borracharia no transporte coletivo". Revista de Transportes Públicos - ANTP, p.77-93, 1986.

VAZ, J.C.: Almoxarifado e materiais de manutenção. Curso de Manutenção Industrial, Instituto Mauá de Tecnologia, 1985. 
ZUCCA, A.J.: Manutenção preventiva caminho a zero defeito. Ed.McGraw-Hill, São Paulo, 1980.

\section{MAINTENANCE MANAGEMENT OF VEHICLE FLEETS: A REVIEW}

ABSTRACT - This paper describes problems and challenges concerning the maintenance area of organizations that operate vehicle fleets, from the management point of view. The maintenance context is characterized from discussions about manpower qualification, informatization level, decision making complexity and the necessities of incorporating quality and productivity into this area.

Key-words: maintenance planning, maintenance management, maintenance control, maintenance of vehicle fleets. 